\title{
Whipple's disease confined to the CNS presenting with multiple intracerebral mass lesions
}

\author{
S J Wroe, M Pires, B Harding, B D Youl, S Shorvon
}

\begin{abstract}
A patient with isolated cerebral Whipple's disease presented with signs of raised intracranial pressure and multiple ring enhancing intracerebral mass lesions evident on CT and MRI imaging. Characteristic intracellular bacilliform inclusions were identified in a brain biopsy. Clinical improvement followed treatment with parenteral antibiotics for two weeks and long term sulphamethoxazole-trimethoprim. As CNS relapse of Whipple's disease may occur after several years, long term treatment should include antibiotics that are able to cross the blood-brain barrier.
\end{abstract}

The National Hospital,

London

$S \mathrm{~J} W$ roe

S Shorvon

Department of

Neuropathology and

Multiple Sclerosis

NMR Research

Group, ${ }^{\star}$ Institute of

Neurology, London

M Pires

B Harding

B D Youl*

Correspondence to

Dr Wroe, The Nationa

Hospital, Queen Square,

London WCIN 3BG, UK

Received 6 December 1990

and in revised form

20 March 199

In 1907 Whipple described a 36 year old medical missionary with a five year history of flitting arthritis, weight loss and productive cough who presented to the Johns Hopkins Hospital with intermittent fever, abdominal distension and steatorrhoea. ${ }^{1}$ Anaemia, erythema nodosum, severe wasting, dyspnoea and peripheral oedema were noted and the patient died two days after an exploratory laparotomy. Pathological examination revealed widespread deposition of neutral fats and fatty acids, particularly in the small intestine and lymph nodes, with vacuolation and giant foamy mononuclear cells containing rod shaped bacilli. Whipple concluded that the
Accepted 5 April 1991

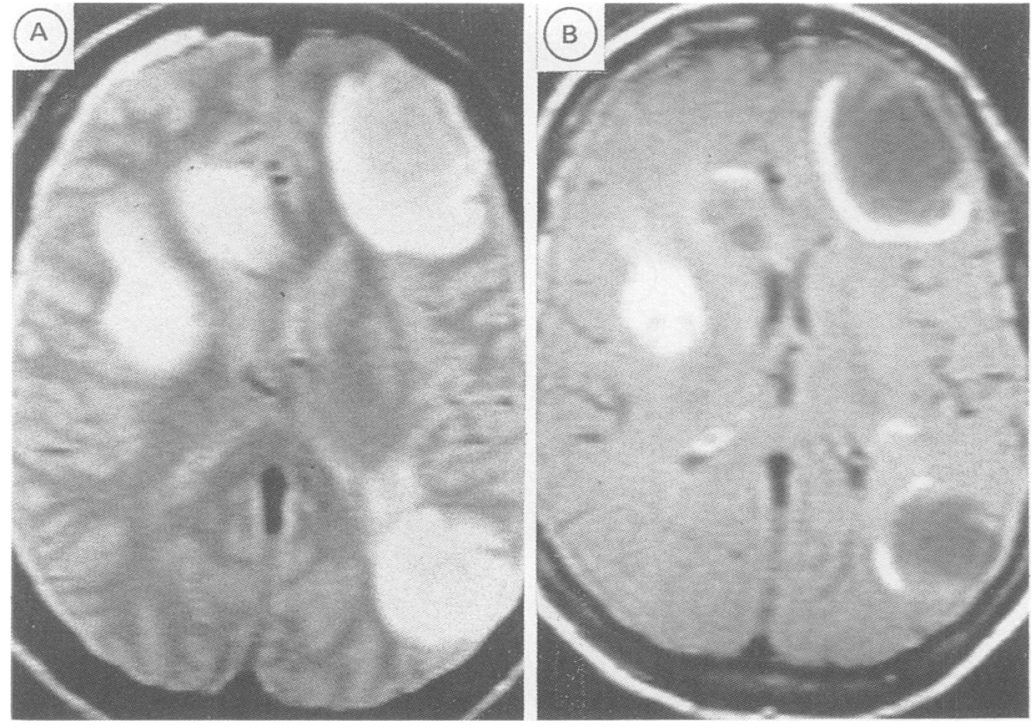

Figure $1 M R I$ scans (a) $S E_{2000,60}$. There are multiple large high signal mass lesions. (b) After gadolinium-DTPA $(0.1 \mathrm{mmol} / \mathrm{kg})$ lesions show peripheral ring enhancement. There is only slight surrounding oedema. The apparently homogeneous enhancement of the right lateral frontal lesion is due to a tangential section. disease was disorder of fat metabolism, and suggested the term "intestinal lipodystrophy". Subsequent studies with periodic acid Schiff (PAS) staining identified the phagocytosed intracellular material as glycoprotein. ${ }^{2}$ Although a bacterial cause remains unproven, the associated intracellular bacillus has been characterised in detail ${ }^{3}$ and probably plays an aetiological role in Whipple's disease.

Neurological symptoms frequently occur during the course of the illness ${ }^{45}$ but progressive cognitive decline and hypothalamic disturbance leading to death are rare. ${ }^{67} \mathrm{We}$ report a patient with Whipple's disease that was confirmed by biopsy and confined to the CNS illustrating the diagnostic difficulties in these cases. CT and MRI scans showed multiple ring enhancing intracerebral mass lesions, a finding not previously described in this condition.

\section{Case report}

A 32 year old white heterosexual policeman was admitted in December 1989 with a two week history of increasingly severe morning headaches, vomiting and drowsiness. In the few days before admission, his wife reported that he was less responsive, and more sleepy than usual. There had been no preceding fever, rashes, diarrhoea, or other systemic upset.

Examination showed him to be drowsy and disorientated. He was apyrexial and had no rash, lymphadenopathy or other abnormality on general examination. Minimal bilateral papilloedema was evident on fundoscopy; he had a left upper motor neuron seventh nerve palsy, slight left sided pyramidal weakness and sensory inattention with symmetrical brisk limb reflexes and flexor plantar responses.

Routine investigations were all normal. CSF examination showed the presence of oligoclonal bands (absent from paired serum) but was otherwise normal. Serum and CSF examination for mycobacteria, viral and fungal antibodies including HIV, cryptococcus and toxoplasma were negative. A CT head scan showed multiple bilateral ring enhancing mass lesions. An MRI scan (Picker 0.5T) showed multiple high signal mass lesions with peripheral ring enhancement following the injection of gadolinium-DTPA (fig 1). Psychometry showed a verbal IQ of 71 and performance IQ of 53 on the WAIS-R with memory impairment, perceptual difficulties and evidence of frontal lobe dysfunction. 
Figure 2 MRI scan showing considerable enlargement of the left frontal mass which is now compressing the lateral ventricle and causing other lesions have decreased in size. midline displacement. The

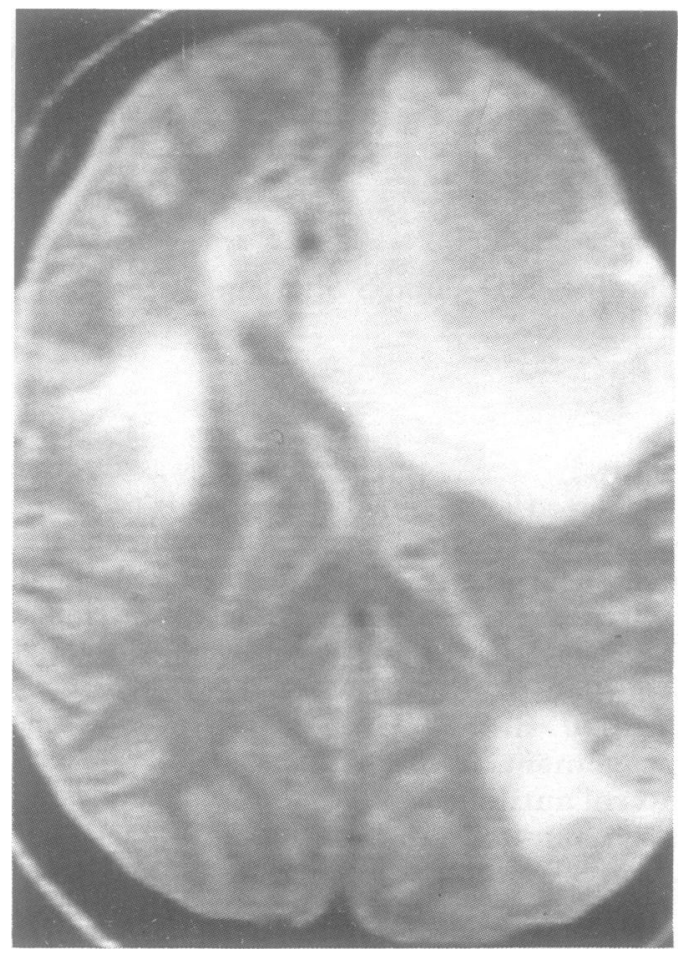

Partial excision of the partly cystic right frontal lesion was performed at open craniotomy. Post operatively the patient was treated with intravenous penicillin and streptomycin together with oral tetracycline for two weeks and then continuous oral sulphamethoxazole-trimethoprim (co-trimoxazole). Gastroscopy and multiple duodenal and jejunal biopsies were all normal.

One month later his condition was only slightly improved. He was apathetic, docile, and did not initiate conversation. He showed some intellectual improvement but had to be led to the table to eat. MRI showed most of the lesions to be smaller though there was considerable enlargement of the left frontal mass (fig 2). Psychometry showed a verbal IQ of 73 and performance IQ of 58.

The patient was reviewed after a further two months by which time his condition had

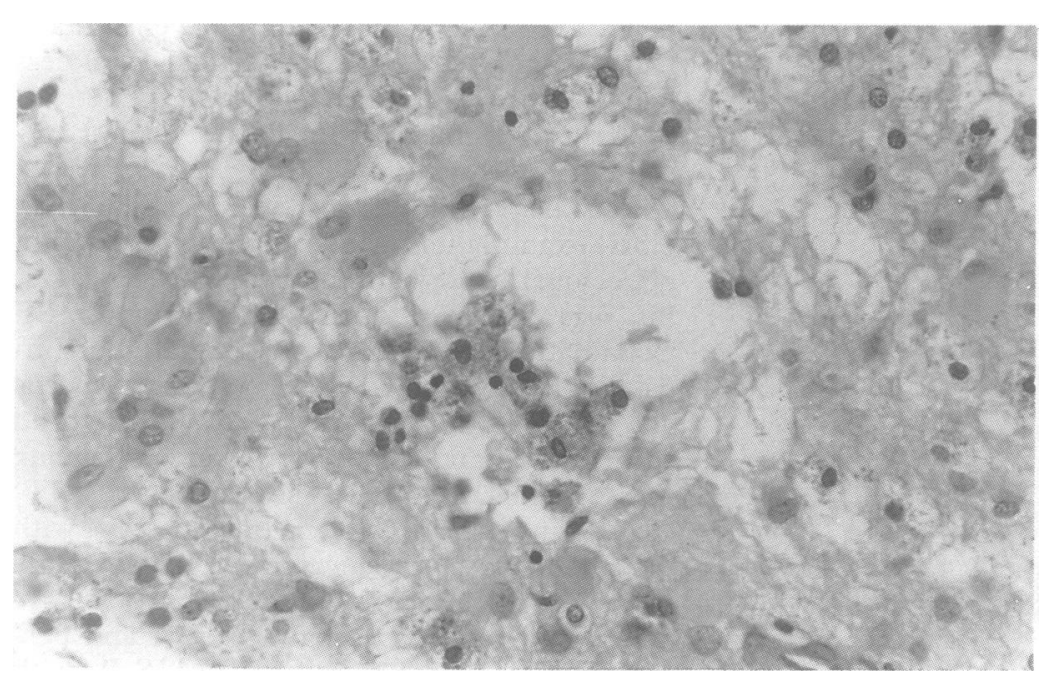

Figure 3 A group of foamy macrophages containing $P A S$ positive granular material, surrounded by large gemistocytic astrocytes. $(P A S \times 400)$. greatly improved. He was alert and able to find his way to and from the hospital without help. His conversation was appropriate and his mood normal. Recall of the details of his illness and subsequent events was poor, but he was aware of current events. MRI showed improvement or resolution of all intracerebral lesions. Eleven months after onset of the illness he had returned to work in a limited capacity.

\section{PATHOLOGICAL FINDINGS}

The biopsy material was fixed and processed with standard methods for both light and electron-microscopy. Histologically the cortex and white matter were largely replaced by gliovascular tissue. Large numbers of swollen gemistocytic astrocytes and smaller collections of foamy macrophages were present as well as perivascular cuffs of mononuclear cells. Many of the macrophages contained irregular PAS positive, diastase resistant cytoplasmic material (fig 3). Special stains for acid fast bacilli and fungi were negative.

On electron-microscopy the macrophages contained rod-shaped bacilli (fig 4 ), 0.2 by $1.5-2.5 \mu \mathrm{m}$. Although some appeared to be degenerating, better preserved examples had a well defined trilaminar membrane.

\section{Discussion}

This patient presented with symptoms of rapidly evolving raised intracranial pressure with multiple ring enhancing mass lesions on CT and MRI. Electron microscopy of material obtained at open biopsy demonstrated intracellular bacterial inclusions similar to those

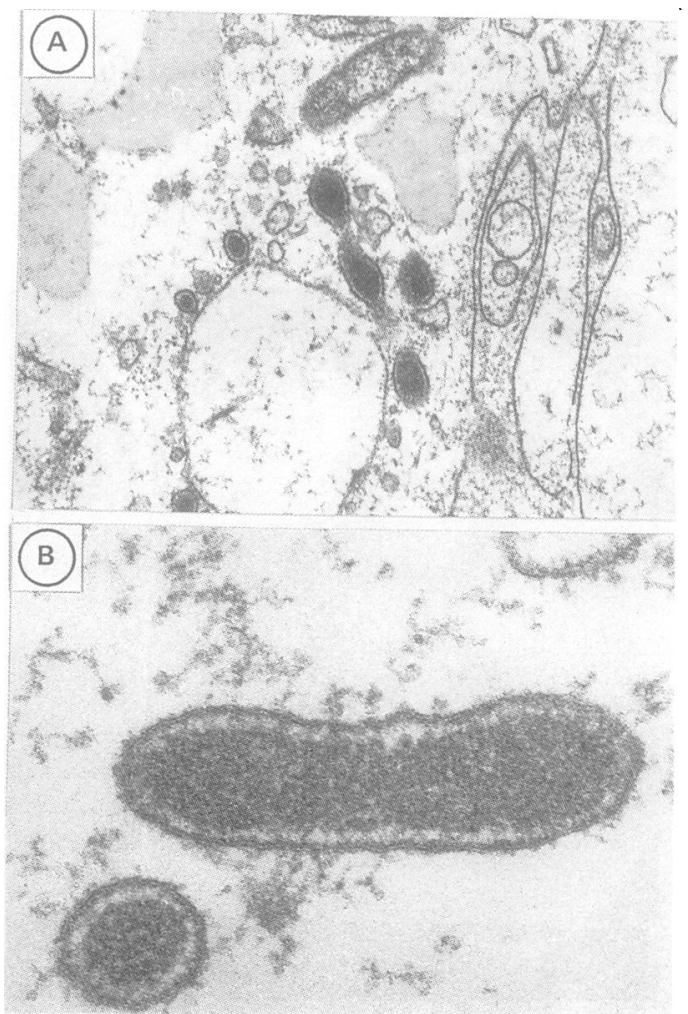

Figure 4 (a) Bacilli within the cytoplasm of a macrophage $\times 26,000$. (b) Detail of bacilli showing the trilaminar plasma membrane $\times 132,000$. 
Table Neurological complications of Whipple's disease

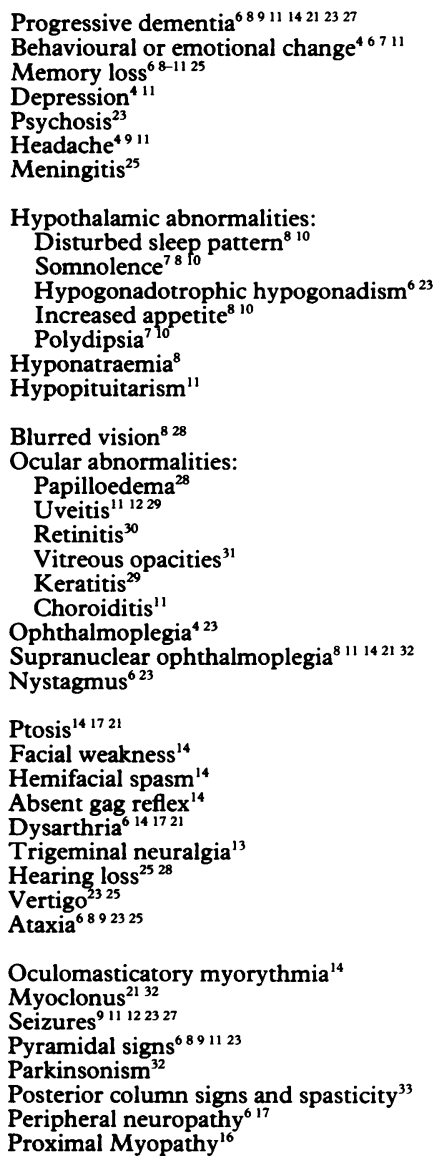

previously described from patients with Whipple's disease. Some immediate improvement followed craniotomy and the start of antibiotic treatment, although cognitive deficits and behavioural changes were not significantly improved until two to three months later.

The majority of patients with Whipple's disease present with arthralgia, gastro-intestinal symptoms or systemic upset, but 5 to $43 \%$ may have CNS involvement when first seen. ${ }^{45}$ The neurological picture is variable (table) and presentation with an exclusively or predominantly neurological picture is uncommon. Progressive cognitive decline, ataxia, hypothalamic disturbance or evidence of brainstem dysfunction with supranuclear ophthalmoplegia have been described in such cases. ${ }^{6-9}$ Jejunal biopsy may be normal ${ }^{10-12}$ and PAS positive cells in the CSF are an inconsistent finding. ${ }^{1013}$ In these circumstances diagnosis is difficult and, as in our patient, may only be established by brain biopsy. ${ }^{12}$ An involuntary movement disorder said to be specific for Whipple's disease has been termed oculomasticatory myorhythmia. ${ }^{14}$ Rhythmic convergence $^{14}$ or verticle pendular ${ }^{15}$ eye movements at one Hertz are accompanied by synchronous opening and closing of the jaw. Peripheral neuropathy and myopathy are reported, but the importance of associated vitamin and nutritional deficiency in these cases remains uncertain since PAS positive macrophages have been identified on muscle biopsy ${ }^{16}$ but not in peripheral nerves. ${ }^{17}$
Abnormalities on CT or MRI scans are not specific for Whipple's disease. CT head scans are often normal ${ }^{18}$ or show cortical atrophy, ${ }^{14} 17$ but areas of low density without mass effect which may show patchy contrast enhancement are described. ${ }^{612}$ MRI shows diffuse abnormalities, especially increased signal on T2 weighted images of the hypothalamus and adjacent medial temporal lobes ${ }^{8}$ but multiple mass lesions with ring enhancement after gadolinium have not previously been described in Whipple's disease.

Detailed EM and cytochemical studies of the Whipple's bacillus in jejunal biopsy specimens from untreated cases reveal a three layered bacterial envelope surrounding free bacilli in the lamina propria. $^{3}$ A $6.08 \mathrm{~nm}$ cytoplasmic membrane is surrounded by a $20 \mathrm{~nm}$ cell wall. This contains peptidoglycan and polysaccharides whose PAS-positive remnants form the characteristic intracellular inclusions. An outer $4.7 \mathrm{~nm}$ surface membrane differs structurally from the outer membrane of Gram negative bacteria.

No immunological abnormalities were evident in our patient and the role of altered immunity in the pathogenesis of Whipple's disease is uncertain. An association with HLA B27 has been suggested ${ }^{19}$ and abnormalities of T lymphocyte function have been reported. ${ }^{20}$ The condition has been described in patients suffering from AIDS and these patients may have cerebral involvement. ${ }^{21}$

Before antibiotic treatment Whipple's disease was uniformly fatal, usually within months ${ }^{422}$ but rapid symptomatic and biochemical improvement of cases with no CNS involvement follows treatment with antibiotics. ${ }^{43}$ Von Herbay reported 22 patients followed up for one to 15 years with no CNS relapses after initial treatment with tetracycline continued for two years ${ }^{24}$, although CNS relapse is reported after shorter courses of tetracycline. ${ }^{4}$ Progressive memory deficit and personality change may occur during otherwise successful treatment and clearance of bacillary organisms from jejunal biopsy specimens. ${ }^{25}$ Relapse is reported in up to $35 \%$ of patients after apparently successful treatment and may be delayed. ${ }^{23}$ Keinath et al identified 88 patients by literature review and correspondence who had been followed up for at least two years after diagnosis or one year after completing therapy. ${ }^{23}$ Relapse occurred in 31 patients at a mean of 4.2 years after diagnosis and relatively more frequently after initial treatment with tetracycline or penicillin alone than after combined penicillin, streptomycin, tetracycline or trimethoprim-sulphamethoxazole. CNS relapse was most common, occurring in $11(13 \%)$ of patients, all more than two years after diagnosis. Six of these patients died and four others responded poorly to further treatment. Similarly presentation with neurological symptoms usually indicates a bad prognosis, most cases responding poorly to treatment and dying within months or a few years of diagnosis. ${ }^{689}$

Since late CNS involvement may follow initial therapy with tetracycline it has been suggested that patients should be treated with 
drugs that are better able to cross the bloodbrain barrier and a single case report exists which describes reversal of progressive dementia in a patient with Whipple's disease treated with trimethoprim-sulphamethoxazole. ${ }^{18}$ For this reason our patient was treated with parenteral penicillin and streptomycin for 14 days followed by long term oral trimethoprim-sulphamethoxazole. ${ }^{23}$

Macrophage bacterial inclusion associated CNS disease appears to have a poor prognosis whether or not associated with systemic Whipple's disease. Efforts in such cases should be directed towards identifying specific causative organisms and long term treatment with antibiotics known to cross the blood-brain barrier. ${ }^{26}$ Further information is required to determine whether CNS involvement occurs in other cases of Whipple's disease with a good outcome, and to determine the relative importance of immune deficiency and direct bacterial invasion in the pathogenesis of the condition. Long term follow up studies would help identify the optimum antibiotic regime and duration of treatment.

The Multiple Sclerosis NMR Research Group is supported by the Multiple Sclerosis Society of Great Britain and Northern Ireland.

1 Whipple GH. A hitherto undescribed disease characterized anatomically by deposits of fat and fatty acids in the intestinal and mesenteric lymphatic tissues. Johns Hopkins Med Bull 1907;198:382-91.

2 Black-Schaffer B. The tinctorial demonstration of a glycoprotein in Whipple's disease. Proc Soc Exp Biol Med 1949; 72:225-7.

3 Silva MT, Macedo PM, Moura-Nunes JF. Ultrastructure of bacilli and the bacillary origin of the macrophagic inclusions in Whipple's disease. J Gen Microbiol 1985; 131:1001-13.

4 Fleming JL, Wiesner RH, Shorter RG. Whipple's disease: clinical, biochemical, and histopathologic features and assessment of treatment in 29 patients. Mayo Clin Proc 1988;63:539-51.

5 Hodgson HJF. Whipple's disease. In: Weatherall DJ, Leningham JGG, Warrell DA, eds. Oxford textbook of medicine. Oxford: OUP, 1987:636-7.

6 Halperin JJ, Landis DM, Kleinman GM. Whipple disease of the nervous system. Neurology 1982;32:612-7.

7 Kitamura T Brain Involvement in Whipple's Disease. Acta Neuropathol 1975;33:275-8.

8 Adams M, Rhyner PA, Day J, De Armond S, Smuckler EA.
Whipple's disease confined to the central nervous system. Ann Neurol 1987;21:104-8.

9 Romanul FCA, Radvany J, Rosales RK. Whipple's disease confined to the brain: a case studied clinically and pathologically. J Neurol Neurosurg Psychiatry 1977;40:901-9.

10 Feurle GE, Volk B, Waldherr R. Cerebral Whipple's Disease with negative jejunal histology. $N$ Engl $J$ Med 1979;300:907-8.

11 Finelli PF, McEntee WJ, Lessell S, Morgan TF, Copetto J. Whipple's Disease with Predominantly Neuroophthalmic Whipple's Disease with Predominantly Neu

12 Johnson L, Diamond I. Cerebral Whipple's Disease. $A m$ Clin Pathol 1980;74:86-490.

13 Stoupel N, Monseu G, Pardoe A, Heimann R, Martin JJ Encephalitis with Myoclonus in Whipple's Disease. $J$ Neurol Neurosurg Psychiatry 1969;32:338-43.

14 Hausser-Hauw C, Roullet E, Robert R, Marteau R. Oculofacio-skeletal myorhythmia as a cerebral complication of systemic Whipple's disease. Mov Disord 1988;3:179-84.

15 Knox DL, Bayless TM, Pitman FE. Neurologic disease in patients with treated Whipple's disease. Medicine 1975; 55:467-76.

16 Swash M, Schwartz MS, Vandenburg MJ, Pollock DJ. Myopathy in Whipple's Disease. Gut 1977;18:800-4.

17 Cooper TJ, Bird G, White B, Ferguson IT. Recovery from Bilateral Wrist-Drop in Whipple's Disease. J Neurol Neurosurg Psychiatry 1988;51:152-4.

18 Ryser RJ, Locksley RM, Eng SC, Dobbins-WO-3d, Schoenknecht-FD, Rubin CE. Reversal of dementia associated with Whipple's disease by trimethoprimsulfamethoxazole, drugs that penetrate the bloodbrain barrier. Gastroenterology 1984;86:745-52.

19 Feurle GE. Association of Whipple's disease with HLA-B27 (letter). Lancet 1985;1:1336.

20 Bjerknes R, Laerum OD, Degaard S. Impaired bacterial degradation by monocytes and macrophages from patient with treated Whipple's disease. Gastroenterology 1985;89:1139-46.

21 Jankovic J. Whipple's Disease of the Central Nervous System in AIDS. NEJM 1986;315:1029-30.

22 Hendrix JP, Black-Schaffer B, Withers RW, Handler P Whipple's Intestinal Lipodystrophy. Arch Intern Med Whipple's Intesti

23 Keinath RD, Merrell DE, Vlietstra R. Dobbins-WO-3d Antibiotic treatment and relapse in Whipple's disease. Long-term follow-up of 88 patients. Gastroenterology 1985;88:1867-73.

24 Herbay von A, Otto HF. Whipple's Disease: A Report of 22 Patients. Klin Wochenschr 1988;66:533-9.

25 Feldman M, Hendler RS, Morrison EB. Acute Meningoencephalitis after Withdrawal of Antibiotics in Whipple's Disease. Ann Intern Med 1980;93:709-11.

26 Wood M, Anderson M. Neurological infections. London: WB Saunders, 1988:21-37.

27 Pollock S, Lewis PD, Kendall B. Whipple's Disease Confined to the Nervous System. J Neurol Neurosurg Psychiatry $1981 ; 44: 1104-9$.

28 Switz DM, Casey TR, Bogaty GV. Whipple's disease and papilledema. Arch Intern Med 1969;123:74-7.

29 Leland TM, Chambers JK. Ocular Findings in Whipple' Disease. South Med J 1978;71:335-8.

30 Font RL, Rao NA, Issarescu S, McEntee WJ. Ocula Involvement in Whipple's Disease. Arch Ophthalmo 1978;96:1431-6.

31 Selsky EJ, Knox DL, Maumenee AE, Green WR. Ocular involvement in Whipple's disease. Retina 1984;4:103-6.

32 Nath A, Jankovic J, Pettigrew LC. Movement disorders and AIDS. Neurology 1987;37:37-41.

33 Koudouris SD, Stern TN, Utterback RA. Involvement of central nervous system in Whipple's disease. Neurology 1963;13:397-404. 